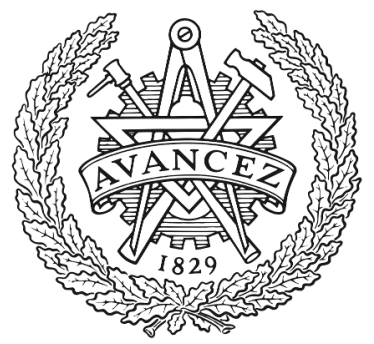

CHALMERS

UNIVERSITY OF TECHNOLOGY

\title{
Aerosol Jet Printing of Graphene and Carbon Nanotube Patterns on Realistically Rugged Substrates
}

Downloaded from: https://research.chalmers.se, 2023-04-26 13:44 UTC

Citation for the original published paper (version of record):

Kaindl, R., Gupta, T., Bluemel, A. et al (2021). Aerosol Jet Printing of Graphene and Carbon

Nanotube Patterns on Realistically Rugged Substrates. ACS Omega, 6(50): 34301-34313.

http://dx.doi.org/10.1021/acsomega.1c03871

N.B. When citing this work, cite the original published paper. 


\title{
Aerosol Jet Printing of Graphene and Carbon Nanotube Patterns on Realistically Rugged Substrates
}

\author{
Reinhard Kaindl,* Tushar Gupta, Alexander Blümel, Songfeng Pei, Peng-Xiang Hou, Jinhong Du, \\ Chang Liu, Paul Patter, Karl Popovic, David Dergez, Kenan Elibol, Erhard Schafler, Johan Liu, \\ Dominik Eder, Dietmar Kieslinger, Wencai Ren, Paul Hartmann, Wolfgang Waldhauser, \\ and Bernhard C. Bayer*
}

Cite This: ACS Omega 2021, 6, 34301-34313

Read Online

ACCESS | Llll Metrics \& More | 回 Article Recommendations | (1) Supporting Information

ABSTRACT: Direct-write additive manufacturing of graphene and carbon nanotube (CNT) patterns by aerosol jet printing (AJP) is promising for the creation of thermal and electrical interconnects in (opto)electronics. In realistic application scenarios, this however often requires deposition of graphene and CNT patterns on rugged substrates such as, for example, roughly machined and surfaceoxidized metal block heat sinks. Most AJP of graphene/CNT patterns has thus far however concentrated on flat wafer- or foiltype substrates. Here, we demonstrate AJP of graphene and single walled CNT (SWCNT) patterns on realistically rugged plasmaelectrolytic-oxidized (PEO) Al blocks, which are promising heat sink materials. We show that AJP on the rugged substrates offers line resolution of down to $\sim 40 \mu \mathrm{m}$ width for single AJP passes,
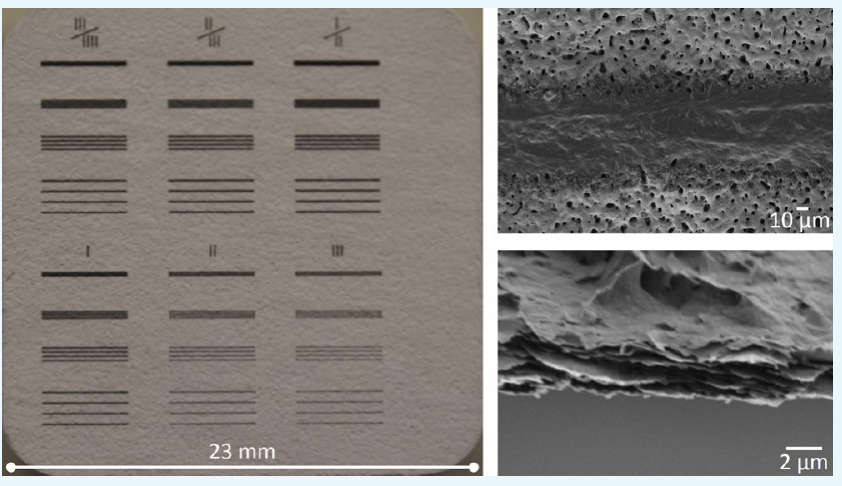
however, at the cost of noncomplete substrate coverage including noncovered $\mu \mathrm{m}$-sized pores in the PEO Al blocks. With multiple AJP passes, full coverage including coverage of the pores is, however, readily achieved. Comparing archetypical aqueous and organic graphene and SWCNT inks, we show that the choice of the ink system drastically influences the nanocarbon AJP parameter window, deposit microstructure including crystalline quality, compactness of deposit, and inter/intrapass layer adhesion for multiple passes. Simple electrical characterization indicates aqueous graphene inks as the most promising choice for AJP-deposited electrical interconnect applications. Our parameter space screening thereby forms a framework for rational process development for graphene and SWCNT AJP on application-relevant, rugged substrates.

\section{INTRODUCTION}

Graphene and carbon nanotubes (CNTs) have exciting properties including record thermal conductivity, ${ }^{1,2}$ exceptionally high current-carrying capability, ${ }^{3,4}$ chemical stability, and mechanical strength. This makes them highly interesting as device elements in electronics, lighting, and sensing. In particular, due to excellent thermal and electrical conductivity, graphene and CNTs are being considered as ideally suited materials for thermal and electrical interconnects in (opto)electronics. $^{1,2}$ Due to continuing device miniaturization, particularly controlled thermal conduction in thermal interconnects to transport dissipation heat from temperaturesensitive device elements to heat sinks is key in modern (opto)electronics. ${ }^{1,2}$ For such thermal interconnects, deposition of the graphene/CNTs as patterned thermal conductors with a good interface to heat sink materials is essential, ${ }^{5}$ in particular, in hybrid printed/surface-mount-technology concepts. ${ }^{6}$ Compared to flat electronic-grade substrates such as wafers or foils, realistic heat sink materials are, however, often comparatively roughly machined metal blocks with highly rugged surfaces ( $\mathrm{Cu}$ or $\mathrm{Al}$ blocks). ${ }^{5}$ Additionally, these metal heat sink blocks are also often electrically insulated by additional processing steps (e.g., oxidation) which can further increase their surface roughness and inhomogeneity. ${ }^{5}$ Therefore, deposition routes for graphene and CNT thermal interconnects must be compatible with such rugged substrate surfaces.

Additive manufacturing such as inkjet printing or aerosol jet printing (AJP) of graphene and CNTs is a versatile route to create thermal and electrical interconnects. ${ }^{7,8}$ Compared to competing "top-down" device fabrication techniques, additive manufacturing has several advantages: ${ }^{7,8}$ first, it allows

Received: July 21, 2021

Accepted: November 25, 2021

Published: December 10, 2021 
Table 1. Overview of Formulation and Properties of the Prepared Inks

\begin{tabular}{|c|c|c|c|c|c|}
\hline ink & dispersed solid & Solvent & additive & $\begin{array}{l}\text { viscosity } \\
(\mathrm{cP})\end{array}$ & $\begin{array}{l}\text { solid carbon loading } \\
\text { (wt \%) }\end{array}$ \\
\hline $\begin{array}{l}\text { graphene aqueous-low viscosity } \\
\text { (graphene aqua-low viscosity) }\end{array}$ & $\begin{array}{l}\text { few-layer } \\
\text { graphene }\end{array}$ & $\mathrm{H}_{2} \mathrm{O}$ & 1.5 wt $\%$ Tween- 80 & 40 & 0.2 \\
\hline $\begin{array}{l}\text { graphene aqueous-high viscosity } \\
\text { (graphene aqua-high viscosity) }\end{array}$ & $\begin{array}{l}\text { few-layer } \\
\text { graphene }\end{array}$ & $\mathrm{H}_{2} \mathrm{O}$ & $\begin{array}{l}1.5 \text { wt } \% \text { Tween- } 80+1 \text { wt } \% \\
\text { sodium CMC }\end{array}$ & 600 & 2.0 \\
\hline graphene $D M F$ & $\begin{array}{l}\text { few-layer } \\
\text { graphene }\end{array}$ & $\begin{array}{l}\text { DMF }(80 \%), \mathrm{H}_{2} \mathrm{O} \\
\quad(20 \%)\end{array}$ & 1.5 wt $\%$ Tween- 80 & 40 & 0.8 \\
\hline graphene DMF with polymer & $\begin{array}{l}\text { few-layer } \\
\text { graphene }\end{array}$ & $\begin{array}{l}\text { DMF }(80 \%), \mathrm{H}_{2} \mathrm{O} \\
\quad(20 \%)\end{array}$ & 1.5 wt $\%$ Tween- $80+1$ wt $\%$ PVP & 80 & 1.2 \\
\hline SWCNT aqueous (SWCNT aqua) & SWCNTs & $\mathrm{H}_{2} \mathrm{O}$ & 2 wt $\%$ sodium cholic acid & 60 & 0.4 \\
\hline
\end{tabular}

deposition of graphene and CNTs on a wide range of substrates without the need for high temperatures and reactive chemical environments, resulting in excellent substrate preservation. Second, additive manufacturing intrinsically results in patterned depositions, thereby foregoing the need for cumbersome postdeposition transfer, lithography, and subtractive etching steps that are needed to obtain device patterns via many other fabrication flows. Third, precursors (inks) for additive manufacturing can be scalably prepared through low-cost liquid-phase processing of graphene and CNTs.

The majority of work on additive manufacturing of graphene and CNTs has to date concentrated on inkjet printing., ${ }^{7,8}$ In inkjet printing, droplets of ink are released from a print head nozzle with a fixed stand-off distance to the substrate to be printed on $(\sim 1 \mathrm{~mm})$. Two key requirements, however, limit inkjet printing: first, the employed inks need to have viscosities $<20 \mathrm{cP},{ }^{9}$ limiting the range of materials and solid content loadings that can be inkjet-printed. Second, the requirement for the fixed nozzle-substrate stand-off distance limits inkjet printing to work best on flat substrates, while it is limited on realistically rugged substrates.

A highly promising alternative direct-write additive manufacturing technique that circumvents these two shortcomings is AJP: $:^{6,9-19}$ in AJP, the material to deposit is suspended within fine aerosol particles that are generated from the AJP ink and then are directed as a collimated stream onto the desired substrate in a patterned fashion. ${ }^{9}$ The use of an aerosol during the deposition widens the range of viscosities of usable AJP inks to $1-1000 \mathrm{cP}$ and consequently allows a wider range of materials and higher solid content loadings to be deposited by AJP than inkjet printing. Additionally, because the AJP aerosol particle stream is collimated through threedimensional gas flow sheathing, variable nozzle-substrate stand-off distances are possible, thereby enabling consistent deposition at a variable $1-5 \mathrm{~mm}$ stand-off range. ${ }^{9}$ This makes AJP highly suited for the deposition on rugged substrates (reaching even three-dimensional printing capabilities). ${ }^{9}$

AJP of graphene $\mathrm{e}^{20-25}$ and CNTs ${ }^{20,26-36}$ has been studied so far in the context of thermal and electrical interconnects, ${ }^{20-23,32}$ transistors, ${ }^{20,26-29,31,33-36}$ and electrochemical sensors. ${ }^{24,25,30}$ Likewise, also, first efforts in AJP deposition of other two-dimensional (2D) materials beyond graphene (e.g., $2 \mathrm{D}$ hexagonal boron nitride, $2 \mathrm{D} \mathrm{BiOCl}$ ) have recently been undertaken. ${ }^{33,37} \mathrm{~A}$ common denominator of these prior studies is, however, that only comparatively flat substrates have been considered, that is, predominantly mirror-finish polished $\mathrm{SiO}_{2}$ coated Si wafers, ${ }^{21-23,26,29,31,34}$ glass plates, ${ }^{28,30}$ and polymeric foils have been used. ${ }^{20,23-25,27,29,32,33,36,37}$ Such flat electronicgrade substrates hold high relevance for device elements in electronics but are less relevant for potential deposition of the nanocarbons as thermal interconnects onto rugged metal heat sinks. ${ }^{5}$ Given AJP's variable range of usable stand-off distances $(1-5 \mathrm{~mm}),{ }^{9}$ AJP is the ideal technique for direct-writing of graphene/CNT patterns on such rugged heat sink materials. To date, no study has, however, investigated AJP of graphene and CNTs on such realistically rugged substrates.

Toward filling this gap, we here investigate the parameter space of AJP of graphene and single-walled CNTs (SWCNTs) on realistically rugged heat sink substrates. In particular, we investigate plasma-electrolytic-oxidized $(\mathrm{PEO})^{38,39} \mathrm{Al}^{\text {blocks }}{ }^{5}$ as substrates for AJP printing of nanocarbons. Such PEO Al blocks are a key material technology for heat sinks in thermal management in industrial light-emitting-diode integration. ${ }^{5} \mathrm{We}$ compare AJP from archetypical aqueous and organic graphene and SWCNT inks via printing of various test patterns on the PEO Al blocks. Morphological, structural, and simple electrical characterization of the patterned AJP deposits across multiple length scales shows the feasibility of AJP printing of graphene and SWCNTs on such realistically rugged substrates.

\section{RESULTS AND DISCUSSION}

Inks. Four graphene inks and one SWCNT ink have been prepared for the AJP experiments (Table 1). Ink formulations cover a wide range of archetypical ink properties including nature of suspension medium ("solvent") (aqueous vs organic), viscosity (visc., 40-600 cP), and solid carbon loading content (0.2-2.0 wt \%). In particular, we prepare (i) few-layer graphene nanosheets ( $\sim 26 \% 1-3$ layers, $\sim 90 \%<9$ layers, lateral sizes $\sim 1$ to $5 \mu \mathrm{m}$ with a mean size of $\sim 3 \mu \mathrm{m}$ ) in water with 1.5 wt \% Tween-80 (graphene aqua-low viscosity), (ii) few-layer graphene nanosheets in water with 1 wt \% sodium carboxymethyl cellulose (CMC) (graphene aqua-high viscosity), (iii) few-layer graphene nanosheets in $N, N$-dimethylformamide (DMF)/water (80:20) (graphene DMF), (iv) fewlayer graphene nanosheets in DMF/water (80:20) with $1 \%$ polyvinyl pyrrolidone (PVP) (graphene DMF with polymer), and (v) SWCNTs in water with 2 wt \% sodium cholic acid surfactant (SWCNT aqua).

Substrates. Substrates were tens of mm-scale, PEO-treated Al blocks (Figure 1a). ${ }^{38,39}$ PEO of the Al blocks results in the formation of an amorphous and porous $\mathrm{Al}_{x} \mathrm{O}_{y}$ layer on $\mathrm{Al}^{38,39}$ Scanning electron microscopy (SEM) and atomic force microscopy (AFM) images in Figure 1b,c show that the $\mathrm{PEO} \mathrm{Al} \mathrm{O}_{y}$ layer comprises a highly rough surface (root-meansquare roughness $\sim 1 \mu \mathrm{m}$ over $50 \mu \mathrm{m} \times 50 \mu \mathrm{m})$ with a large number of $\mu \mathrm{m}$-sized pores $(\sim 1-15 \mu \mathrm{m}$ lateral size; $\sim 5$ pores/ $\left.100 \mu \mathrm{m}^{2}\right)$. The depth of the pores is at minimum up to $\sim 5 \mu \mathrm{m}$ (maximum depth extension of AFM). 

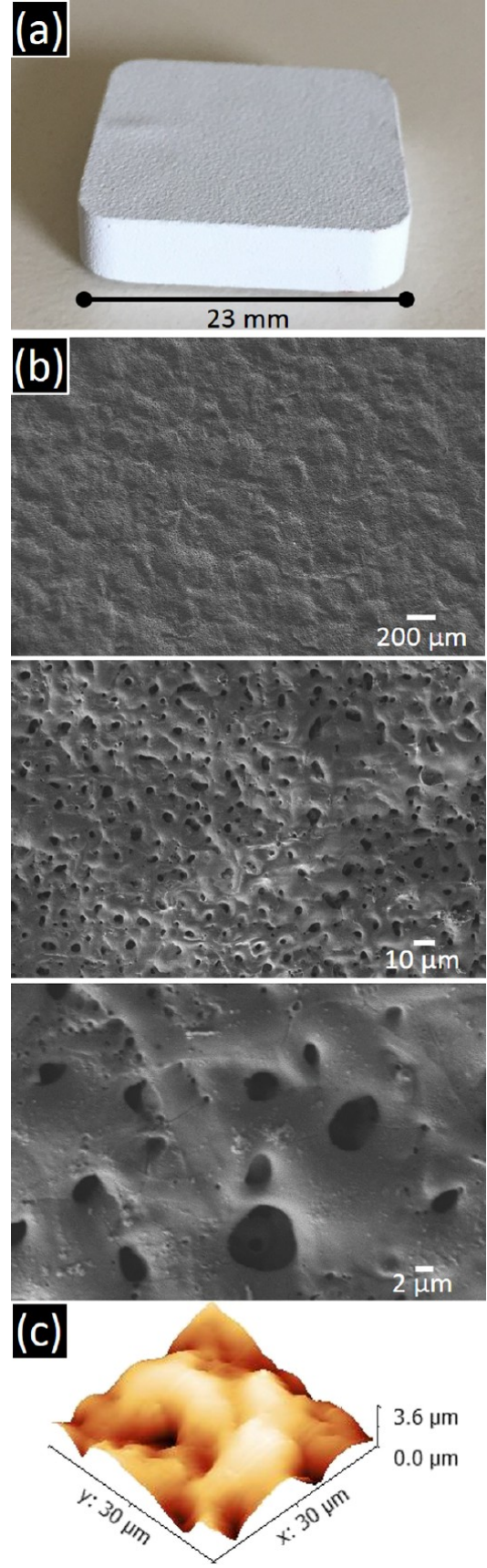

Figure 1. (a) Photograph, (b) top-view SEM micrographs, and (c) top-view AFM topography in three-dimensional plotting of empty PEO Al-block substrates. Two-dimensional plot of AFM data in (c) is shown in Figure S1.

Aerosol Jet Printing. AJP was performed with an Optomec 300 aerosol jet printer system directly on the substrates with all five inks. Exact AJP parameters and further details on ink formulation and substrate preparation are specified in the Methods section below.

Single Pass Lines. As a first assessment of AJP printing resolution and homogeneity, we present in Figure 2 AJP of sets of single pass test lines with all five inks. These single pass test lines were printed in sets of four lines each with interline distances of $50,100,200$, and $500 \mu \mathrm{m}$ at printing nozzle speeds of $0.5,0.67,0.75,1,2$, and $3 \mathrm{~mm} / \mathrm{s}$. A $250 \mu \mathrm{m}$ fine nozzle was used. Photographs in Figure $2 \mathrm{a}-\mathrm{e}$, left, show an overview of the results from the five different inks. Optical microscopy images in Figure $2 \mathrm{a}-\mathrm{e}$, right, show the most illustrative results from the AJP single line sets which include the lines printed at 100 and $200 \mu \mathrm{m}$ interline distances at speeds of $0.5,1$, and 3 $\mathrm{mm} / \mathrm{s}$. To provide higher resolution information, Figure 3 shows the corresponding SEM images of the five inks at 200 $\mu \mathrm{m}$ interline distance at speeds of 0.5 and $3 \mathrm{~mm} / \mathrm{s}$.

Figures $2 \mathrm{a}$ and $3 \mathrm{a}$ show that for graphene aqua-low viscosity at both low and high printing speeds of 0.5 to $3 \mathrm{~mm} /$ $\mathrm{s}$, single pass line widths of $\sim 55 \mu \mathrm{m}$ are readily obtained with a line edge roughness ${ }^{40}$ of $<5 \mu \mathrm{m}$ and little overspray. ${ }^{9,40}$ Single lines are well-isolated from each other, even at low interline distances of only $100 \mu \mathrm{m}$. For graphene aqua-low viscosity, however, only partially homogeneous substrate coverage is obtained at low printing speeds $(0.5 \mathrm{~mm} / \mathrm{s})$ and very poor, patchy coverage is obtained at high printing speeds $(3 \mathrm{~mm} / \mathrm{s})$, as seen in the SEM data in Figure 3a. Notably, pores in the PEO Al-block substrate remain noncovered for all printing speeds. Decreasing coverage with increasing printing speeds is often observed in AJP. ${ }^{11}$ The only partial/poor coverage for single pass lines indicates that for good coverage graphene aqua-low viscosity AJP requires multiple passes under our conditions, see below. The observed morphology of the AJP deposits in Figure $3 \mathrm{a}$ indicates that they consist of interconnected agglomerates of flakes with their basal planes parallel to the substrate, consistent with few-layer graphene deposition. Raman measurements in Figure $4 \mathrm{a}$ show a pronounced $\mathrm{G}$ and $2 \mathrm{D}$ peak and only a small $\mathrm{D}$ peak. ${ }^{41}$ In particular, a $2 \mathrm{D} / \mathrm{G}$ intensity ratio of $\sim 0.3$ is consistent with few-layer graphene and the low $\mathrm{D} / \mathrm{G}$ intensity ratio of $\sim 0.09$ indicates that the few-layer graphene is of high quality, similar to the high-quality starting graphite crystals for the ink preparation. This indicates that neither ink preparation nor AJP printing has degraded the crystalline quality of the fewlayer graphene flakes in aqua-low viscosity.

Figures $2 \mathrm{~b}$ and $3 \mathrm{~b}$ show the results for graphene aqua-high viscosity. Single pass line widths of $\sim 50 \mu \mathrm{m}$ are obtained at low $(0.5 \mathrm{~mm} / \mathrm{s})$ and high $(3 \mathrm{~mm} / \mathrm{s})$ printing speeds. Lines are well-isolated from each other. For low $(0.5 \mathrm{~mm} / \mathrm{s})$ speeds, line edge roughness is $<5 \mu \mathrm{m}$ and coverage from the single passes is largely complete, albeit with a stronger overspray than for the aqua-low viscosity-deposits. In contrast, for higher printing speeds $(3 \mathrm{~mm} / \mathrm{s})$, lines from the single pass show only very poor, patchy coverage. The SEM images in Figure $3 b$ of the low printing speed lines $(0.5 \mathrm{~mm} / \mathrm{s})$ indicate that they consist of interconnected agglomerates of flakes with their basal plane parallel to the substrate. This is again consistent with few-layer graphene deposition. Consistently, the Raman data in Figure $4 \mathrm{~b}$ correspond to the few-layer graphene assignment $(2 \mathrm{D} / \mathrm{G}$ : $\sim 0.25$ ) and further indicate that the few-layer graphene is of high quality (D/G: $~ 0.05)$ and hence was not degraded during ink preparation and AJP. However, even for these largely homogeneously covering lines from low printing speeds $(0.5$ $\mathrm{mm} / \mathrm{s}$ ), pores in the PEO Al-block substrate are not covered by nanocarbon deposits but remain noncovered.

Figures $2 c, d$ and $3 c, d$ show the AJP results from graphene in organic DMF-based inks. In particular, Figures $2 c$ and $3 c$ present the single pass results for graphene DMF ink. In contrast to the aqueous printing mentioned above, where defined lines were printed under all conditions, we observe for $\mathrm{DMF}$, a very strong difference in printing results depending on printing speed: for low speeds $(0.5-0.75 \mathrm{~mm} / \mathrm{s})$, no lines are obtained but rather an undefined, patchy area network of 


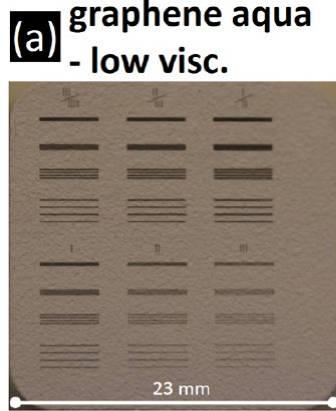

graphene aqua - high visc.

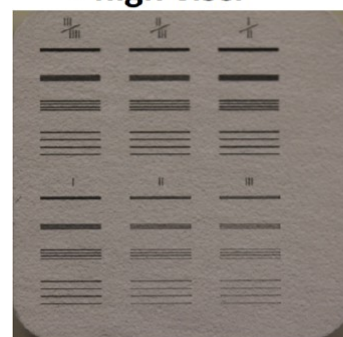

(c) graphene DMF

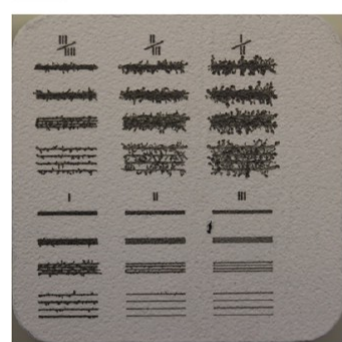

graphene DMF with polymer

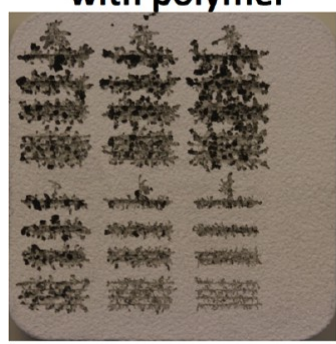

(e) SWCNT aqua

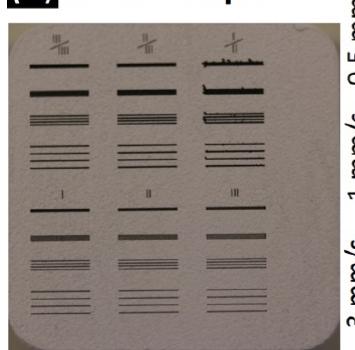

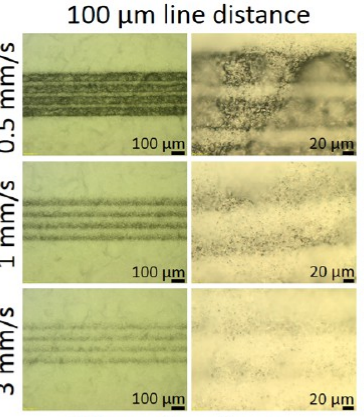

$100 \mu \mathrm{m}$ line distance

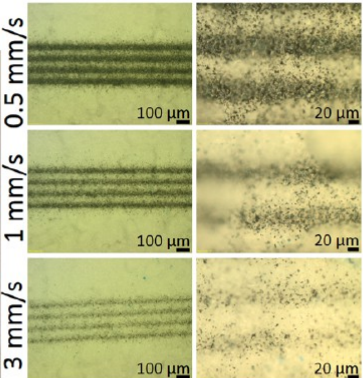

$100 \mu \mathrm{m}$ line distance

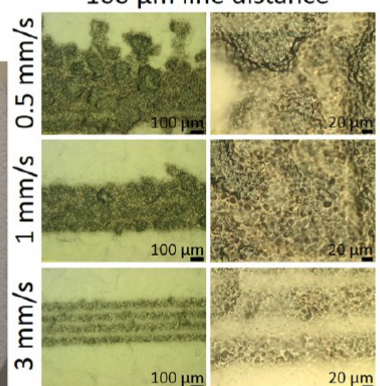

$100 \mu \mathrm{m}$ line distance

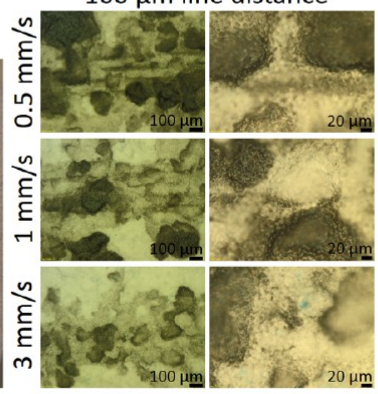

$100 \mu \mathrm{m}$ line distance

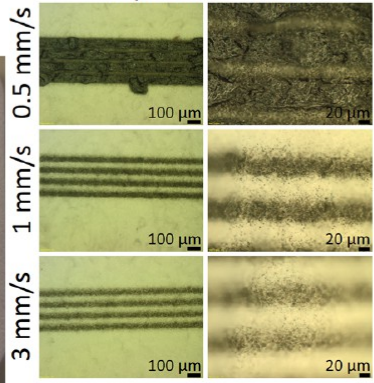

$200 \mu \mathrm{m}$ line distance

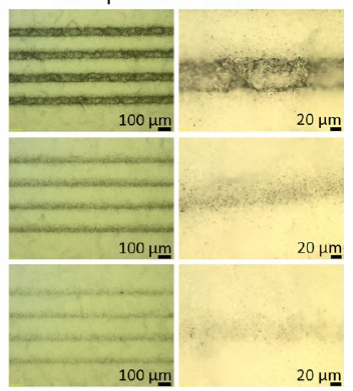

$200 \mu \mathrm{m}$ line distance

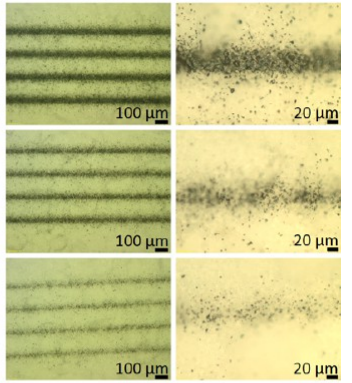

$200 \mu \mathrm{m}$ line distance

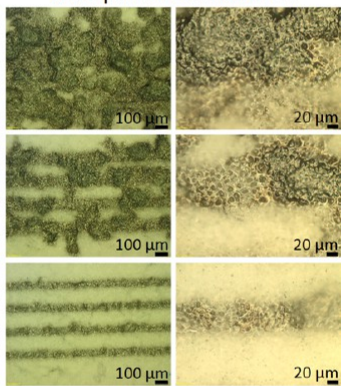

$200 \mu \mathrm{m}$ line distance

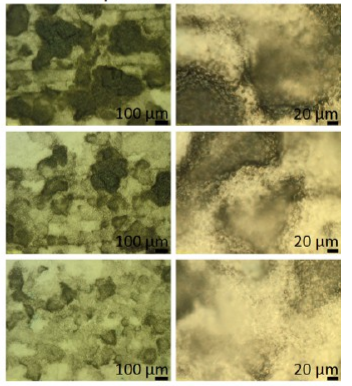

$200 \mu \mathrm{m}$ line distance

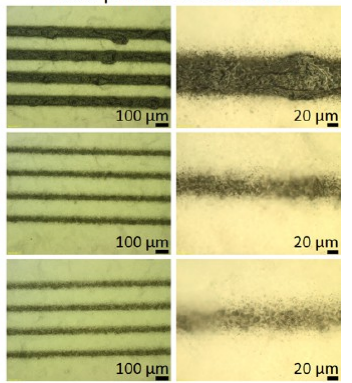

Figure 2. (a-e) Top-view photographs of the entire AJP single pass test patterns on the PEO Al-block substrates (left) and top-view optical microscopy at varying magnifications (right) of selected single pass AJP lines on the PEO Al blocks for all five inks.

deposits, which is also laterally smeared out over several 100 $\mu \mathrm{m}$. At intermediate printing speeds $(1 \mathrm{~mm} / \mathrm{s})$, a beginning definition of lines emerges but the separate single pass lines still are smeared out to widths (up to $100 \mu \mathrm{m}$ ) larger or comparable to their width $(\sim 50 \mu \mathrm{m})$. Therefore, no single, isolated lines are obtained but interconnected line networks are obtained. Only at higher printing speeds $(>2 \mathrm{~mm} / \mathrm{s})$, defined lines are obtained. For $3 \mathrm{~mm} / \mathrm{s}$, we obtain defined and isolated lines with line widths $\sim 60 \mu \mathrm{m}$, line edge roughness $<5 \mu \mathrm{m}$, and largely continuous and close to complete coverage. However, 

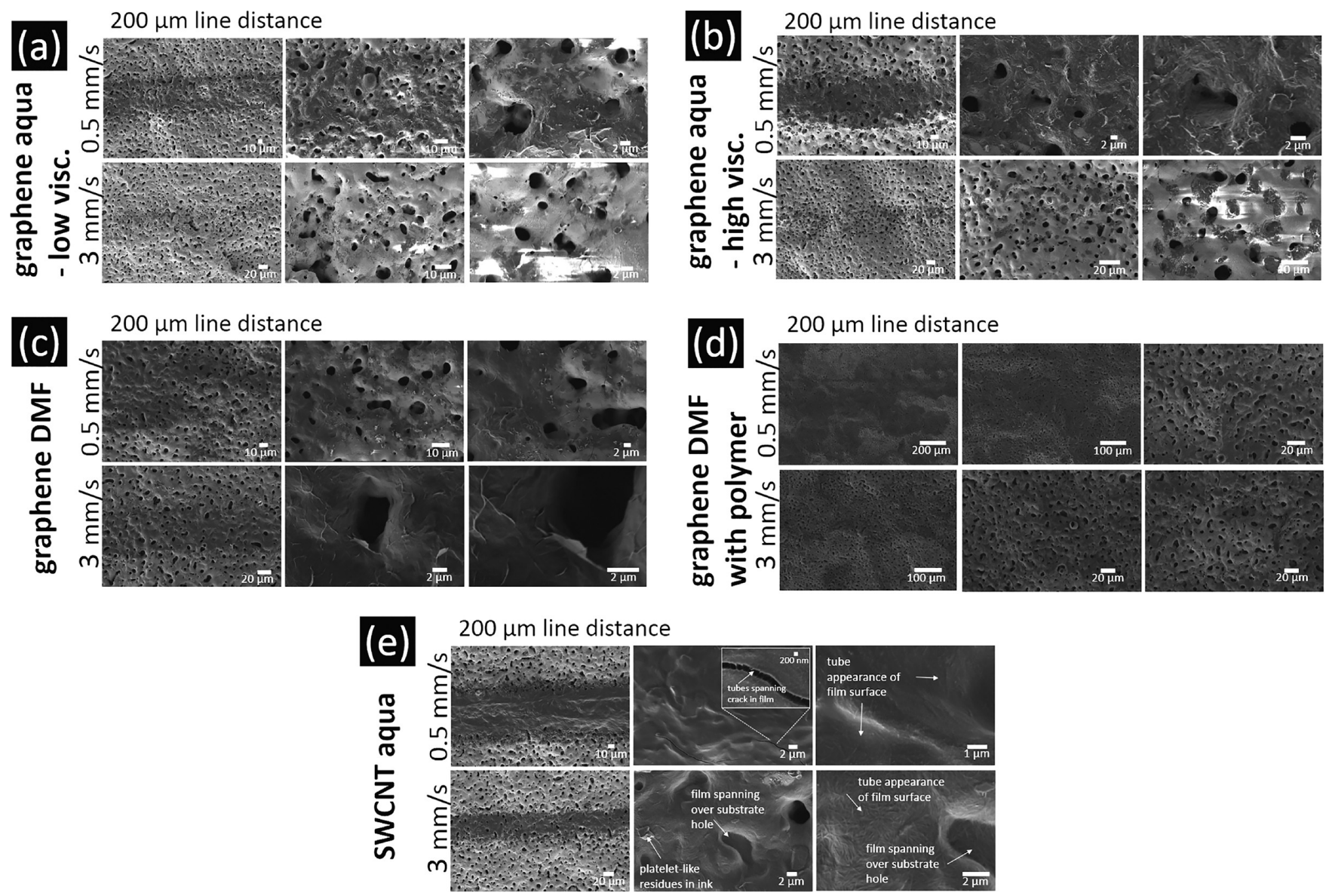

Figure 3. (a-e) Top-view SEM micrographs at varying magnifications of selected single pass AJP lines on PEO Al blocks for all five inks.

pores in the PEO Al-block substrate remain noncovered from the single passes. The morphology of the DMF AJP deposits in Figure 3c,d appears not as clear nanoflake morphology (as in the aqueous AJP in Figure 3a,b) but rather as a compact, dense film in which nanoflake edges and folds are visible. Raman spectroscopy results in Figure $4 \mathrm{c}$ indicate that the DMF film consists of few-layer graphene (2D/G: $\sim 0.3)$. Compared to the aqueous results in Figure $4 a, b$, the DMF few-layer graphene is, however, of crystalline lower quality, as evidenced by a significantly higher $\mathrm{D} / \mathrm{G}$ ratio of $\sim 0.6{ }^{41}$ This indicates that the DMF AJP route results in slightly degraded graphene deposit quality, which is in line with the prior literature. ${ }^{42,43}$

For the DMF with polymer AJP, we find for the single line passes in Figures $2 \mathrm{~d}$ and $3 \mathrm{~d}$ that no defined printing of lines is obtained under any of the tested printing speeds. Instead, under all conditions, we obtain an undefined, patchy area network of deposits that are smeared over several $100 \mu \mathrm{m}$. The SEM image in Figure $3 \mathrm{~d}$ and Raman spectroscopy results in Figure $4 \mathrm{~d}$ indicate that deposits are few-layer graphene (2D/G: $\sim 0.2$ ) of somewhat degraded crystalline quality ( $\mathrm{D} / \mathrm{G}: \sim 0.7$ ) in dense, compact deposits, similar to DMF.

The observation that for DMF-based solvents, the line definition becomes better with increasing printing speed is somewhat counter-intuitive yet can be explained by low adherence and slow drying of DMF-based AJP droplets on the substrates. This results in the passing gas sheath of the AJP to blow the droplets over the substrate surface before they can dry, thus degrading line definition. For higher printing speeds, the AJP gas sheath moves fast enough away from the landed droplets so that drying in place and within defined line patterns can occur. The different dependence of optimal line coverage and resolution with printing speed for aqueous graphene inks (see above) and DMF-based inks indicates that these two different solvents have clearly different optimum points of printing speed for a given AJP carrier gas flow (here, largely fixed, see the Methods section) as recently modeled by Mahajan et al. ${ }^{11}$

Finally, we show in Figures $2 \mathrm{e}$ and $3 \mathrm{e}$ the AJP single pass printing result of aqueous SWCNT inks. For SWCNT aqua, we obtain very good line definition for all printing speeds. At slow printing speeds $(0.5 \mathrm{~mm} / \mathrm{s})$, single pass line widths of $\sim 70 \mu \mathrm{m}$ were obtained with a line edge roughness of $<8 \mu \mathrm{m}$. This results for the $100 \mu \mathrm{m}$ interline distance in almost merging lines, while at $200 \mu \mathrm{m}$ interline distance, isolated lines are obtained. With increasing printing speed to $3 \mathrm{~mm} / \mathrm{s}$, line widths decrease to $\sim 40 \mu \mathrm{m}$ with a line edge roughness of $<5$ $\mu \mathrm{m}$ and isolated lines were obtained for all higher scan speeds. Medium overspray is observed at all printing speeds. At all printing speeds, the SWCNT aqua lines are highly homogeneously covering the substrate. For low printing speeds $(0.5$ $\mathrm{mm} / \mathrm{s}$ ), the lines appear very thick in the SEM image in Figure $3 \mathrm{e}$ and importantly cover almost all pores in the PEO Al-block substrate. On a nanoscopic level, SWCNT aqua deposits are well-resolved as shown in Figure $3 \mathrm{e}$ to be composed of an agglomeration with spaghetti-like morphology of tubular objects with few-nm diameters, consistent with bundles of SWCNTs. ${ }^{44,45}$ Accordingly, the Raman spectrum shown in Figure $4 \mathrm{e}$ is also consistent with that of high-quality 

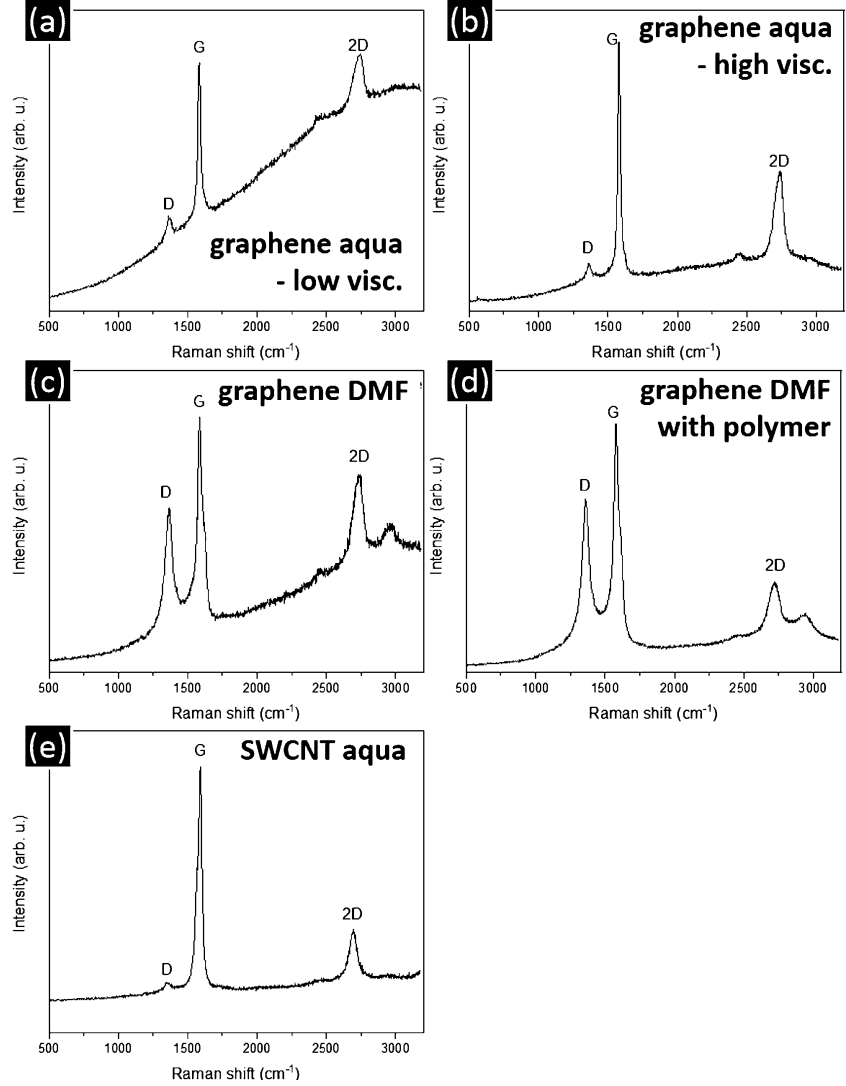

Figure 4. (a-e) Raman spectra measured on the selected single pass AJP lines on PEO Al blocks for all five inks.

SWCNTs. ${ }^{44,45}$ A zoom-in SEM image (Figure 3e $0.5 \mathrm{~mm} / \mathrm{s}$, inset in middle panel) of an inadvertent crack in the aqueous SWCNT AJP deposit shows that SWCNTs remain spanning across the crack. Notably, on the deposit top surface, no individual tube bundles are found to protrude out, suggesting that all SWCNTs are well-embedded into the AJP deposits (when no crack occurs). In addition to the spaghetti-like SWCNTs, few platelet-like objects of few- $\mu \mathrm{m}$ size are also covered/embedded in the SWCNT deposits. We identify these objects further below by X-ray diffractometry (XRD) as surfactant residues from the sodium cholic acid surfactant ${ }^{46}$ in the SWCNT aqua ink. This is corroborated by localized energy-dispersive X-ray (EDX) spectroscopy analysis (Figure S2) that reveals that these objects include Na. Importantly, for both the $0.5 \mathrm{~mm} / \mathrm{s}$ printing speed and the $3 \mathrm{~mm} / \mathrm{s}$ printing speed, all pores and the majority of pores in the PEO Al-block substrate are fully covered by SWCNT aqua AJP deposits, respectively. This is unlike for the graphene AJP (aqua or DMF) deposits mentioned above and illustrates that SWCNT aqua spaghetti networks form a mechanically stable AJP line coating over the rugged, porous substrate even for only single pass lines.

Our data on AJP single pass lines show that for graphene aqua inks, line resolution and definition are good at all printing speeds, but coverage is mostly not fully continuous and pores in the PEO Al-block substrate remain noncovered. This suggests that for graphene aqua inks, multiple passes are necessary for homogeneous coverage. In contrast, graphene DMF inks resulted, in most conditions, in no defined line printing but only an undefined, smeared-out patchy area network. Only graphene DMF at high printing speeds $(\sim 3$ $\mathrm{mm} / \mathrm{s}$ ) resulted in well-resolved and defined lines (which we link to interplay of droplet drying and AJP gas sheath). However, also, for these conditions, only close to complete coverage and no coverage of PEO Al-block pores is achieved. This indicates that multiple passes would also be beneficial for achieving complete substrate coverage including pores with graphene DMF inks. In contrast to the graphene inks, SWCNT aqua resulted in well-resolved and defined lines with complete coverage and majority PEO Al-block pore coverage for most printing conditions already from AJP single passes.

Multiple Pass Lines. In order to uncover whether multiple AJP passes can achieve complete coverage for graphene inks and which effects multiple AJP passes can have for the SWCNT aqua ink, we present in Figure 5 photographs (left), SEM images (middle), and XRD patterns (right) for 10 passes over $15 \mathrm{~mm} \times 6 \mathrm{~mm}$ area patterns written by a $3 \mathrm{~mm}$ wide nozzle in three lines with $2 \mathrm{~mm}$ spacing on the PEO Al-block substrates. All 10 pass patterns were deposited at printing speeds of $2.5 \mathrm{~mm} / \mathrm{s}$.

Photographs and SEM images clearly show complete areal coverage for the 10 pass printing for graphene aqua-low viscosity (Figure 5a), graphene DMF with polymer (Figure $5 \mathrm{~b}$ ), and SWCNT aqua (Figure 5c) inks. This shows that also for graphene DMF with polymer inks, defined AJP with a controlled coverage of substrates is possible for multiple passes (unlike for the single pass AJP above). For aqua-low viscosity (Figure 5a) and SWCNT aqua (Figure 5c), also, the PEO Alblock pores are fully covered, while for DMF with polymer (Figure 5b), some, but not all pores, are covered by the multiple pass AJP.

The SEM images of surface morphology of the graphene aqua-low viscosity (Figure 5a, middle) exhibit interconnected agglomerates of flakes with their basal plane parallel to the substrate, consistent with few-layer graphene and the single pass results mentioned above. Accordingly, the Raman spectroscopy result of the graphene aqua 10 passes (Figure S3a) is akin to the single pass results in Figure $4 \mathrm{a}$ and indicates few-layer graphene of high crystalline quality. We note that in Figure 5a (middle), a fraction of the flake edges appear oriented not fully parallel but with an angle to the substrate, giving the overall surface a somewhat crumpled and rough appearance. XRD patterns in Bragg-Brentano geometry in Figure 5a (right) detect as phases only the Al-block substrate and graphene reflections for the (002) reflection family. This observation of graphene with (002) texture is consistent with few-layer graphene with its layers oriented parallel to the substrate. The observation of the graphene (002) reflections is also consistent with high-crystalline quality of the few-layer graphene, in line with the Raman results in Figure S3a.

For the graphene DMF with polymer ink, the surface morphology in the SEM images exhibits nanoflakes in a compact dense film with some nanoflake edges and folds protruding (Figure $5 \mathrm{~b}$, middle). This is again consistent with the single pass data shown in Figure 3d. The XRD pattern in Figure $5 \mathrm{~b}$ (right) does detect the Al-block substrate and only a very weak, diffuse reflection at the position of graphene (002). This indicates a lower degree of macroscopic flake ordering and/or lower crystalline graphene quality in the DMF ink 10 pass lines compared to the graphene aqua ink in Figure 5a (right). The corresponding Raman data in Figure S3b indicate a lower crystalline quality of the few-layer graphene in the DMF ink (in line with the single pass data in Figure 4d). Combined with the cross-sectional and transmission electron 

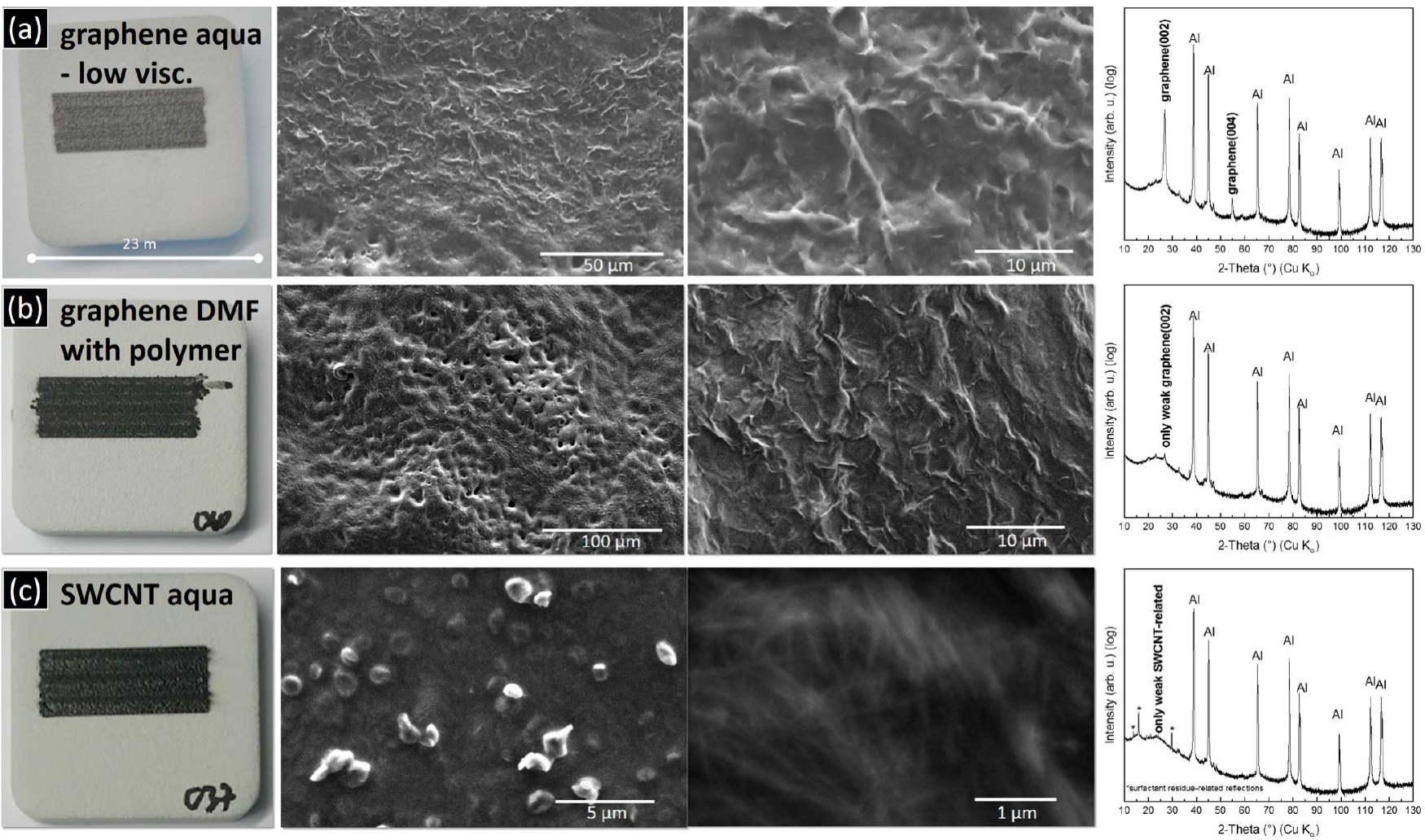

Figure 5. Top-view photographs (left), top-view SEM micrographs at varying magnifications (middle), and XRD patterns (right) of the 10 pass AJP pattern on the PEO Al-block substrates for (a) graphene aqua-low viscosity (b) graphene DMF with polymer, and (c) SWCNT aqua. In the XRD patterns, reflections from salient phases have been labeled. Reflections matching sodium cholate in (c) have been marked by “*”. Note that $\mathrm{XRD}$ intensity is plotted in the log scale to underscore the scattering from the $\mu \mathrm{m}$-thin nanocarbon deposits on the much thicker, mm-thick Alblock substrates.

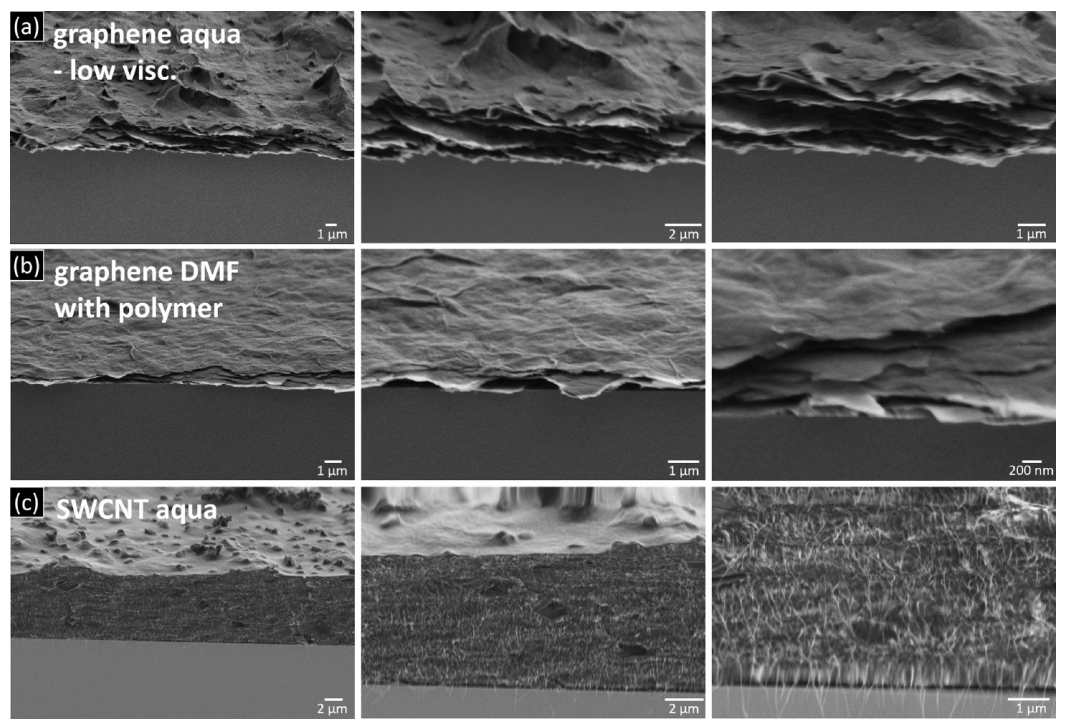

Figure 6. Cross-sectional SEM micrographs at varying magnifications for 10 pass depositions of (a) graphene aqua-low viscosity (b) graphene DMF with polymer, and (c) SWCNT aqua on glass slides. Glass slides have been cleaved by hand to obtain the cross-sectional fracture surfaces of the AJP deposits. The corresponding top-view data are shown in Figure S4.

microscopy (TEM) data given below, this indicates that graphene flakes in the 10 pass DMF deposit are macroscopically mostly ordered parallel to the substrate but are microscopically of lower crystalline quality [resulting in $\mathrm{D} / \mathrm{G}$ ratio $\sim 0.6$ in the Raman spectra in Figure S3b and only diffuse halo in the XRD pattern in Figure 5b (right)].
Surface morphology in the SEM image of the 10 pass SWCNT aqua ink in Figure 5c (middle) is consistent with the single pass data in Figure $3 \mathrm{e}$, exhibiting spaghetti-like agglomerates of tubular objects. The Raman spectrum in Figure S3c indicates good SWCNT quality. ${ }^{44,45}$ We note that in addition to the spaghetti-like morphology, a sizeable number of platelet-like objects are also detected on the SWCNT aqua 

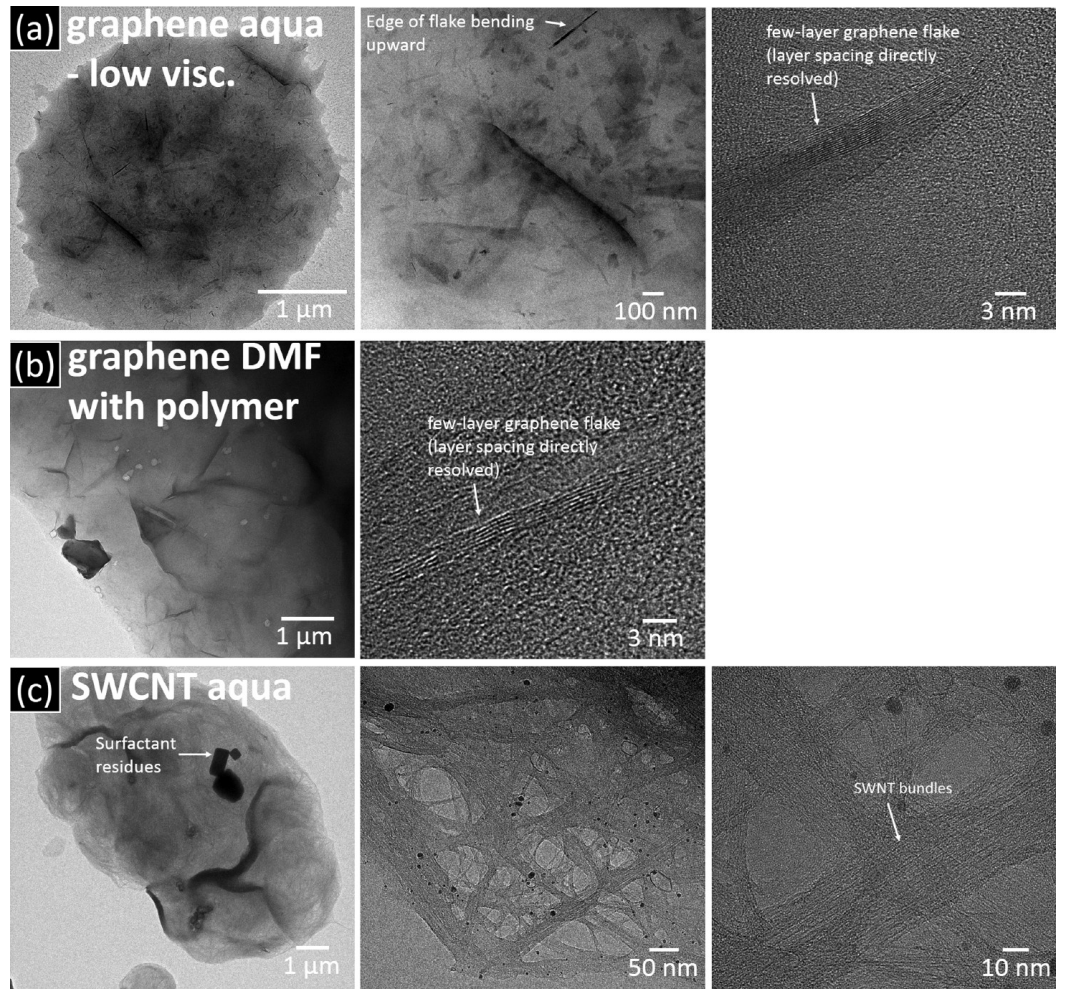

Figure 7. Top-view TEM micrographs at varying magnifications for single pass depositions of (a) graphene aqua-low viscosity (b) graphene DMF with polymer, and (c) SWCNT aqua on SiN TEM membranes.

AJP deposit surface for the 10 pass AJP. XRD data in Figure 5c (right) detect the Al-block substrate, a weak graphitic (002) reflection, consistent with SWCNT films, and also a pattern consistent with sodium cholate crystals. ${ }^{46}$ Since sodium cholate was the surfactant employed in SWCNT aqua ink preparation, the latter observation of the sodium cholate pattern in XRD together with the identification of $\mathrm{Na}$ in the platelet-like objects (via EDX, see above and Figure S2) identifies these platelets as residual surfactants ${ }^{46}$ from ink preparation.

Our 10 pass AJP data show that we can readily print homogeneously covering, continuous nanocarbon films on the rugged PEO Al block via multiple AJP passes. Particularly, for graphene aqua and SWCNT aqua inks, this also includes full coverage of the pores on the PEO Al blocks.

Cross-Sectional SEM and Top-View TEM. To obtain further insights into the microstructure of the AJP depositions of the graphene aqua, graphene DMF with polymer, and SWCNT aqua inks, we also investigate such nanocarbon AJP deposits in cross section by SEM, as shown in Figure 6, and at high magnification in top view by lattice-resolution TEM, as shown in Figure 7 . Since the $\sim 6 \mathrm{~mm}$-thick PEO Al blocks are, however, difficult to cross-section without possible degradation of the nanocarbon deposits, we deposit 10 pass AJP lines under the same AJP conditions on commercial glass slides as model substrates (Figure S4). These glass slides can be conveniently cleaved by hand to obtain nanocarbon layer cross-sectional fracture surfaces perpendicular to the printing direction without prior degradation to the nanocarbon deposits. Additionally, the flatter glass slides allow us an estimation of nanocarbon deposit thickness from both the cross section and profilometry over the printed lines (Figure S5), both of which are not directly obtainable on the rugged PEO Al-block substrates. Likewise, the PEO Al blocks are too thick to enable electron transparency for top-view TEM without the need for possibly degrading, severe thinning of specimens. Thus, for top-view TEM studies, we print single lines of the nanocarbons directly onto SiN TEM membranes ( $20 \mathrm{~nm}$ SiN thickness). We emphasize that switching from the rugged PEO Al-block substrates to the glass slides for cross-sectional and $\mathrm{SiN}$ membranes for TEM can also impact AJP results to some extent due to, for example, the differences in roughness and surface energies between the substrates. We, however, find the overall insights from the AJP deposits on the glass slides and $\mathrm{SiN}$ to be instructive nevertheless and also to corroborate our findings from optical microscopy, SEM, Raman spectroscopy, and XRD data of the PEO Al-block samples mentioned above (Figure S4).

Figure 6a shows that for graphene aqua-low viscosity after 10 passes, a fully covering graphene film is obtained. Consistent with the top-view SEM data in Figure 5a, the cross-sectional SEM image indicates that the printed graphene aqua deposits include nonflat regions with $\mu \mathrm{m}$-height protrusions of flakes at an angle to the substrate ("tent-like" structures). For the 10 passes, we measure an average deposit thickness of $\sim 2 \mu \mathrm{m}$, placing an average single pass deposition thickness on the order of $\sim 200 \mathrm{~nm}$. The thickness estimation from the SEM cross section is also corroborated by profilometry across a 10 pass graphene aqua line shown in Figure S5a. The 10 pass deposit morphology is visible in Figure 5 a to be composed of several sublayers all roughly parallel to the substrate. These sublayers are ascribed to be composed of multiple restacked few-layer graphene flakes. The number of visible sublayers is roughly consistent with the 10 individual AJP passes. Thus, the visible separation of the AJP film into the sublayers at the cross-sectional fracture surface indicates that during each AJP pass, the material deposited from this pass is 
better adhering among each other (i.e., forming a sublayer) than adherence between the material from different passes is; that is, intrapass adherence is greater than interpass adherence. This may be related to drying dynamics of a deposited sublayer during the timespan before the next pass (sublayer) gets deposited.

Figure $6 \mathrm{~b}$ accordingly shows cross-sectional SEM data for graphene DMF with polymer. Consistent with top-view data in Figure 5a, the DMF ink films appear more compact than the graphene aqua films. The DMF ink film also has fewer and shallower $\mu \mathrm{m}$-height protrusions than the graphene aqua film. 10 pass thickness for graphene DMF with a polymer is $\sim 1 \mu \mathrm{m}$, placing single pass deposit thickness on the order of $\sim 100 \mathrm{~nm}$ (again consistent with profilometry data in Figure S5b). Also, the DMF ink layer exhibits visible sublayers at the fracture surface, again roughly consistent with the number of passes and indicating lower interpass than intrapass adherence.

Figure 6c shows cross-sectional SEM images of SWCNT aqua 10 passes. Consistent with the top view-SEM data over a crack in Figure 3e inset, we find the fracture surface to be composed of tubular objects protruding out. This is consistent with the SWCNT spaghetti-type microstructure observed above. Also, in agreement with top-view SEM image in Figures $3 e$ and $5 c$, we find a sizeable number of platelet-like sodium cholate acid surfactant residues. Importantly, the crosssectional SEM images indicate that these sodium cholate acid residues are present not only toward the film surface but also embedded within the film volume. 10 pass film thickness for the SWCNT aqua ink is $\sim 7 \mu \mathrm{m}$, placing single pass thickness on the order of $\sim 700 \mathrm{~nm}$. Such a comparatively larger thickness is also largely corroborated by profilometry in Figure S5c. The observation that single pass thickness is larger for the SWCNT aqua ink than for graphene aqua and graphene DMF inks is also consistent with the top-view SEM observations shown in Figure 3. Interestingly, and unlike for the graphene inks, the individual passes of SWCNT aqua ink do not separate into sublayers at the fracture surface. Individual pass sublayers are only faintly discernible via a faint seam in the SEM image at higher magnification shown in Figure $6 c$. This indicates that interpass adherence is close to intrapass adherence for the SWCNT aqua ink (unlike for the graphene inks).

Figure $7 \mathrm{a}$ investigates the microstructure of the graphene aqua-low viscosity AJP deposits at high resolution via topview TEM. The single pass drop shows in TEM features consistent with the SEM characterization mentioned above: most graphene flakes are deposited with their basal planes parallel to the substrate in film morphology. Some flakes are, however, bending upward at their edges. While such bending macroscopically eventually results in the "tent-like" structure observed in Figure 6a, in TEM, upward bent flakes allow direct graphene layer counting by providing a "side view" of the layers. In the example shown in Figure 7a, we identify a flake with $\sim 13$ graphene layers, thus consistent with the overall fewlayer graphene nature of the graphene aqua ink.

In Figure $7 \mathrm{~b}$, similar top-view TEM characterization of the graphene DMF with polymer ink is presented. Similar to the graphene aqua film, the DMF ink results in a compact film structure with few-layer graphene flakes with their basal planes parallel to the substrate. This corroborates our assertion from above that the XRD graphitic (002) for DMF inks in Figure 5b is low not due to low macroscopic sheet alignment but due to low(er) crystalline quality of the individual few-layer graphene flakes, which is in agreement with the high $\mathrm{D} / \mathrm{G}$ ratio $\sim 0.6$ in the Raman data in Figures 4d and S3b. Again, few flakes have their edges bent upward, allowing direct graphene layer counting and corroborating the few-layer graphene assignment ( $\sim 6$ layers in Figure $7 b)$.

Figure $7 \mathrm{c}$ finally extends the top-view TEM investigation to the SWCNT aqua ink. For this ink, we find in TEM, the AJP deposits to be not composed of isolated SWCNTs but bundles of SWCNTs (Figure 7c). Bundling is typical for SWCNTs. ${ }^{44}$ This shows that the tubular objects observed in the SEM images in Figures 3e, 5c, and 6c were bundles of SWCNTs and not isolated SWCNTs. Also, consistent with SEM and XRD data, we also find platelet-like sodium cholic acid surfactant residues in the TEM image shown in Figure $7 c$.

Combined, our cross-sectional SEM and top-view TEM observations are consistent with top-view SEM, XRD, and Raman characterizations mentioned above. This suggests that our characterization has captured intrinsic properties of the graphene and SWCNT AJP deposits across multiple length scales. Importantly, the observed consistency of characterization results between AJP on rugged $\mathrm{PEO} \mathrm{Al}$ blocks and typical, flat glass benchmark substrates also highlights that AJP is indeed capable of producing nanocarbon pattern deposits on realistically rugged PEO Al-block substrates that are on par with results on the typical flat benchmark glass substrates. This reaffirms the initial motivation of this study of advantageously employing AJP to print nanocarbon patterns on otherwise hard-to-handle and less-studied realistically rugged substrates.

Electrical Characterization. Having established from our microstructural observations mentioned above that our multipass pattern AJP depositions result in homogeneously covering, continuous films on the PEO Al blocks, we also perform first simple electrical characterization of these films. This allows us to assess which films are the most promising for future application screening as electrical (or thermal) interconnects. To this end, we measure sheet resistances of our films using a multiple-contact two-terminal transmission line model (TLM) method, ${ }^{47}$ allowing us an order of magnitude comparison of sheet resistances (and resistivities) for the various AJP nanocarbon films. Sheet resistances and the corresponding resistivities for films on PEO Al blocks are presented in Table 2. An exemplary TLM data set is presented in Figure S6, and the corresponding sheet resistances and resistivities for films on glass substrates are presented in Table $\mathrm{S} 1$. For all films, we find electrical conduction over $\mathrm{mm}$ scales, reaffirming our conclusion from microstructure character-

Table 2. Measured Sheet Resistances for the 10 Pass AJP Samples on PEO Al Blocks ${ }^{a}$

$\begin{array}{lcc}\text { samples (10 pass) on PEO Al block } & \text { sheet resistance } & \text { resistivity }(\Omega \mathrm{m}) \\ \text { graphene aqua-low viscosity } & \sim 11 \Omega / \square & \sim 2 \times 10^{-5} \\ \text { graphene DMF with polymer } & \sim 275 \mathrm{k} \Omega / \square & \sim 2.75 \times 10^{-1} \\ \text { SWCNT aqua } & \sim 100 \mathrm{k} \Omega / \square & \sim 7.00 \times 10^{-1}\end{array}$

${ }^{a}$ Resistivities were calculated from sheet resistances, assuming that the films on PEO Al blocks have similar thicknesses as the films on the glass substrates (graphene aqua-low viscosity: $2 \mu \mathrm{m}$, graphene DMF with polymer: $1 \mu \mathrm{m}$, and SWCNT aqua: $7 \mu \mathrm{m}$ ). Bare PEO Al-block substrates exhibit no electrical conduction under our measurement conditions, suggesting sheet resistances of $>2 \mathrm{M} \Omega / \square$. For an exemplary TLM data set from which sheet resistance was extracted, see Figure S6. For the corresponding data for AJP deposits on flat benchmark glass substrates, see Table S1. 
ization that all multipass films are continuous. Notably, we find that the sheet resistance and resistivity values for the graphene aqua-low viscosity films are several orders of magnitude lower compared to the graphene DMF with polymer and SWCNT aqua films. This suggests that the graphene aqua-low viscosity films are the most promising for electrical interconnect applications. We attribute this to higher intraflake conduction due to a higher crystalline quality of the graphene aqua deposits (indicated by Raman spectra in Figures 4 and S2) and/or better interflake conduction due to a lower degree of solvent and surfactant residues in the graphene aqua films compared to the other films (Figures 3, 5, and 7). Comparison with the literature shows that obtained sheet resistance $(\sim 11$ $\Omega / \square)$ and resistivity $\left(\sim 2 \times 10^{-5} \Omega \mathrm{m}\right)$ values for the graphene aqua-low viscosity films are on par with other recent reports on AJP films. ${ }^{21,24}$ We also find that the sheet resistance and resistivity values for the same films printed on flat glass benchmark substrates are similar to the ones on PEO Al-block substrates (Table S1). This again reaffirms that AJP results are of similar quality on the rugged PEO Al-block substrates as on the flat glass benchmark substrates, again highlighting the suitability of AJP to print high-quality nanocarbon patterns onto realistically rugged substrates.

Further AJP Parameter Optimization. We finally briefly discuss limitations of our here-presented study. Our data give a comprehensive overview of the microstructural dependence of AJP deposits from five medium- and high-viscosity (40 to 600 $\mathrm{cP}$ ) nanocarbon inks. Our AJP parameter screening focused, in particular, on AJP printing speed and compared fine nozzle $(250 \mu \mathrm{m})$ single-line and wide nozzle $(3 \mathrm{~mm})$ multiple-line printing, while other AJP parameters (sheath and carrier gas flows, stage temperatures, etc.) remained largely fixed in our work. Clearly, printing speed and nozzle size are not the only parameters that can critically influence AJP printing results. In this context, we note, for instance, that based on a recent model $^{11}$ developed by Mahajan et al. which has been derived from studying one single lower-viscosity ink (silver nanoparticle ink with $1-5 \mathrm{cP}$, compared to the 5 nanocarbon inks with 40 to $600 \mathrm{cP}$ used here), the focusing ratio (sheath gas flow rate/carrier gas flow rate) was identified as another important parameter to optimize line definition and coverage. Since the focusing ratio remained in our experiments largely fixed at low values ( 0.1 to 0.5 , see the Methods section), screening of focusing ratio dependence for our here-introduced nanocarbon inks could be a fruitful avenue for further improvements to line resolution and coverage. Another possible avenue for future study includes postdeposition processing (e.g., annealing in various atmospheres) of the asprinted AJP deposits. Particular to the SWCNT aqua ink, reducing the amount of surfactant during ink preparation should avoid the formation of the platelet-like surfactant residues. Finally, future work will also need to investigate in greater detail the electrical and the thermal transport properties of the here-introduced various nanocarbon deposits on the rugged substrates and their correlation with the nanocarbon microstructure.

\section{CONCLUSIONS}

In summary, our exploration of parameter space of graphene and SWCNT AJP has demonstrated the feasibility of AJP of nanocarbons on realistically rugged PEO Al-block substrates. We have shown that AJP of the nanocarbons can offer line resolutions down to $\sim 40 \mu \mathrm{m}$ line width with line edge roughness $<5 \mu \mathrm{m}$ for single passes, albeit at the cost of noncomplete coverage and without coverage over the $\mu \mathrm{m}$-sized pores in the PEO Al-block substrates. With multiple passes, full coverage of the rugged substrates including full coverage of the $\mu \mathrm{m}$-sized pores is, however, readily achieved. The choice of the ink system between aqueous and organic (here DMF) solvents with or without additional additives is shown to have a key impact on the AJP results. For instance, our results showed that adjustment of key parameters such as printing speed between different inks is key to controllable nanocarbon AJP pattern deposition. The choice of ink also impacts drastically on the nanocarbon AJP deposit microstructure including crystalline quality, compactness of deposit, and inter/intrapass adhesion in multiple passes. Simple electrical characterization suggests aqueous graphene inks as the most promising choice for electrical interconnect applications. Importantly, we find that our AJP deposits on rugged PEO Al blocks are on par in terms of properties with AJP printing on normally used, benchmark flat glass substrates. This further affirms that AJP is highly suited to print nanocarbon patterns on realistically rugged substrates. Our here-presented nanocarbon AJP parameter space screening thereby forms a rational basis for further future application screening of such deposited AJP graphene and SWCNT patterns as electrical and thermal interconnects on technologically relevant, realistically rugged substrates.

\section{METHODS}

Ink Formulation. Four graphene inks and one SWCNT ink were prepared, according to Table 1. Graphene consisted of a scalable intercalation-exfoliation method ${ }^{48}$ and surfactantassisted dispersion, yielding few-layer graphene nanoflakes with $\sim 26 \%<3$ layers and $\sim 90 \%<9$ layers and lateral sizes of $\sim 1$ to $5 \mu \mathrm{m}$ with a mean size of $3 \mu \mathrm{m}$. ${ }^{49,50}$ For preparation of graphene inks, first, the surfactant solution containing $1.5 \mathrm{wt} \%$ Tween-80 was used to disperse graphene powder. After sonication and centrifugation, a graphene paste with a solid content of $12 \mathrm{wt} \%$ was fabricated for further synthesis of inks. The graphene aqua-low viscosity ink was prepared by direct redispersing of the graphene paste in distilled water to form a solution with a concentration of $2 \mathrm{wt} \%$. The graphene aqua-high viscosity ink was made from the graphene aqua-low viscosity ink by adding sodium CMC powder to reach a CMC concentration of 1 wt \%. The DMF ink was prepared by adding $20 \mathrm{~g}$ of $12 \mathrm{wt} \%$ aqueous paste into $80 \mathrm{~g}$ of DMF, and the mixture was sonicated for $30 \mathrm{~min}$ to form a stable dispersion. The DMF ink with a polymer was prepared by adding PVP (K-60) powder into the DMF ink to reach a PVP concentration of 1 wt $\%$. SWCNTs were prepared by floating catalyst chemical vapor deposition ${ }^{51}$ and were dispersed in water using $2 \mathrm{wt} \%$ sodium cholate acid as a surfactant via tip sonication. ${ }^{51}$ Viscosity of inks was measured using an NDJ-5S rotary viscometer (Shanghai Changji Geological Instrument Co., Ltd.) at room temperature.

Substrate Preparation. Substrates were commercially sourced crude die-cast $99.5 \%$ pure (1050 alloy) Al blocks $(\sim 23 \mathrm{~mm} \times 23 \mathrm{~mm} \times 6 \mathrm{~mm})$. In order to better replicate the surface quality of real-life (die-cast or other) heat sinks, these substrates were planarized using a hydraulic press with a custom-made tool for the substrate size. Subsequently, the substrates have been treated by commercially available PEO (Meotec GmbH, Germany), ${ }^{38,39}$ resulting in the formation of an amorphous $\mathrm{Al}_{x} \mathrm{O}_{y}$ layer on the $\mathrm{Al}$ blocks (amorphous nature 
of $\mathrm{Al}$ oxide confirmed by XRD). All presented data were acquired on the PEO Al-block substrates, apart from the crosssectional SEM data for which lines were printed via AJP onto commercial glass slides that were subsequently cleaved perpendicular to the AJP lines to obtain the cross sections of the deposits and apart from the TEM samples for which AJP depositions were made directly onto $20 \mathrm{~nm}$ SiN TEM membranes (Plano, Germany).

Aerosol Jet Printing. AJP was performed with an Optomec 300 aerosol jet printer, printing directly on the substrates. For the single pass line test structures, the following deposition parameters have been used: nozzle size: $250 \mu \mathrm{m}$ (fine nozzle), bath temperature: room temperature, stage temperature: $50{ }^{\circ} \mathrm{C}$ (to help in ink solvent drying), type of atomizer: pneumatic $\left(\mathrm{N}_{2}\right)$, sheath gas: $\mathrm{N}_{2}$, printing velocities between 0.5 and $3 \mathrm{~mm} / \mathrm{s}$, sheath gas flow: $70 \mathrm{sccm}$, atomizer gas flow: between 560 and $720 \mathrm{sccm}$, and exhaust gas flow: between 525 and $690 \mathrm{sccm}$ (initially selected based on viscosity values of the inks). This equates to a focusing ratio ${ }^{11}$ of $\sim 0.1$. The test patterns consisted of straight lines with various interline distances between 50 and $500 \mu \mathrm{m}$, printed at nozzle speeds of $0.5,0.67,0.75,1,2$, and $3 \mathrm{~mm} / \mathrm{s}$. For the multiple pass line samples, the following deposition parameters have been used: nozzle size: $3 \mathrm{~mm}$ (wide nozzle), bath temperature: room temperature, stage temperature: $50{ }^{\circ} \mathrm{C}$ (to help in ink solvent drying), type of atomizer: pneumatic $\left(\mathrm{N}_{2}\right)$, sheath gas: $\mathrm{N}_{2}$, printing velocity $2.5 \mathrm{~mm} / \mathrm{s}$, sheath gas flow: $600 \mathrm{sccm}$, atomizer gas flow: between 1250 and $1600 \mathrm{sccm}$, and exhaust gas flow: between 800 and $1350 \mathrm{sccm}$ (increased flows compared to single pass experiments due to a larger amount of material to deposit with a wider nozzle). This equates to a focusing ratio ${ }^{11}$ of $\sim 0.5$. The 10 pass test patterns consisted of a rectangle $(\sim 15 \mathrm{~mm} \times \sim 6 \mathrm{~mm})$ defined by 3 straight $\sim 15 \mathrm{~mm}$ long lines written adjacent to each other with an interline distance of $\sim 2 \mathrm{~mm}$ and which was written 10 times (i.e., 10 passes). Samples were further characterized after several days of drying under ambient conditions.

Characterization. For morphological characterization of substrates and the as-printed samples, optical microscopy (Olympus), SEM (Zeiss Supra 55 VP and FEI Quanta 250 FEG, $2 \mathrm{kV}$, Everhart-Thornley secondary detector), and AFM (NT-MDT NTEGRA spectra, ${ }^{52}$ tapping mode) were employed. Structural quality of the nanocarbon deposits was assessed by Raman spectroscopy (NT-MDT NTEGRA spectra $^{52}$ at $473 \mathrm{~nm}$ and Horiba Jobin-Yvon LabRAM $800 \mathrm{HR}$ at $532 \mathrm{~nm}$ laser wavelengths, respectively) and XRD (PANalytical X'Pert Pro MPD, Cu $\mathrm{K}_{\alpha}$ at $0.154 \mathrm{~nm}$, BraggBrentano geometry) including qualitative phase analysis by comparison to the International Centre for Diffraction Data (ICDD) using HighScore Plus software. The following ICDD entries have been used for phase identification: graphene/ graphite: 00-056-0159 $\left[\mathrm{PG}_{3} / \mathrm{mmc}(194)\right]$, face-centred-cubic $\mathrm{Al}$ : 04-012-7848 [Fm $\overline{3} m(225)]$, and sodium cholate: 00-0291911. Additional XRD measurements to confirm the amorphous nature of $\mathrm{Al}_{x} \mathrm{O}_{y}$ layers on the PEO Al blocks were performed in a Bruker D8 Discover GADDS (data not shown). High-resolution characterization of morphology and structure employed bright-field TEM (FEI Tecnai F20, $60 \mathrm{kV}$ ). Additionally, EDX in an FEI Quanta 250 FEG SEM with EDAX SDD Octane Elite 55 at $10 \mathrm{kV}$ was employed to check chemical compositions. Thickness measurements on the glass slide samples employed a Veeco Dektak 150 stylus surface profiler. Electrical characterization included sheet resistance measurements at room temperature using a multiple-contact two-terminal TLM method ${ }^{47}$ via an FK technics FK 9450 multimeter with $\sim 1 \mathrm{~mm}$ contact length probes. Further details on electrical characterization methodology are provided in Figure S6.

\section{ASSOCIATED CONTENT}

\section{Supporting Information}

The Supporting Information is available free of charge at https://pubs.acs.org/doi/10.1021/acsomega.1c03871.

Additional AFM, EDX, Raman spectroscopy, profilometry, and electrical characterization data (PDF)

\section{AUTHOR INFORMATION}

\section{Corresponding Authors}

Reinhard Kaindl - MATERIALS-Institute for Surface Technologies and Photonics, JOANNEUM RESEARCH, A8712 Niklasdorf, Austria; Email: reinhard.kaindl@ joanneum.at

Bernhard C. Bayer - Institute of Materials Chemistry, Technische Universität Wien (TU Wien), A-1060 Vienna, Austria; Faculty of Physics, University of Vienna, A-1090 Vienna, Austria; (i) orcid.org/0000-0002-4829-3207; Email: bernhard.bayer-skoff@tuwien.ac.at

\section{Authors}

Tushar Gupta - Institute of Materials Chemistry, Technische Universität Wien (TU Wien), A-1060 Vienna, Austria

Alexander Blümel - MATERIALS-Institute for Surface Technologies and Photonics, JOANNEUM RESEARCH, A8160 Weiz, Austria

Songfeng Pei - Shenyang National Laboratory for Materials Science, Institute of Metal Research, Chinese Academy of Sciences, 110016 Shenyang, P. R. China

Peng-Xiang Hou - Shenyang National Laboratory for Materials Science, Institute of Metal Research, Chinese Academy of Sciences, 110016 Shenyang, P. R. China

Jinhong Du - Shenyang National Laboratory for Materials Science, Institute of Metal Research, Chinese Academy of Sciences, 110016 Shenyang, P. R. China

Chang Liu - Shenyang National Laboratory for Materials Science, Institute of Metal Research, Chinese Academy of Sciences, 110016 Shenyang, P. R. China; 이이.org/00000003-3016-3997

Paul Patter - MATERIALS-Institute for Surface Technologies and Photonics, JOANNEUM RESEARCH, A8160 Weiz, Austria

Karl Popovic - MATERIALS - Institute for Surface Technologies and Photonics, JOANNEUM RESEARCH, A8160 Weiz, Austria

David Dergez - ZKW Elektronik GmbH, A-2700 Wiener Neustadt, Austria

Kenan Elibol - Faculty of Physics, University of Vienna, A1090 Vienna, Austria; (1) orcid.org/0000-0002-8765-2794

Erhard Schafler - Faculty of Physics, University of Vienna, A1090 Vienna, Austria

Johan Liu - Department of Microtechnology and Nanoscience, Electronics Materials and Systems Laboratory, Chalmers University of Technology, Se 41296 Gothenburg, Sweden; (1) orcid.org/0000-0001-9931-1439 
Dominik Eder - Institute of Materials Chemistry, Technische Universität Wien (TU Wien), A-1060 Vienna, Austria; (1) orcid.org/0000-0002-5395-564X

Dietmar Kieslinger - ZKW Elektronik GmbH, A-2700 Wiener Neustadt, Austria

Wencai Ren - Shenyang National Laboratory for Materials Science, Institute of Metal Research, Chinese Academy of

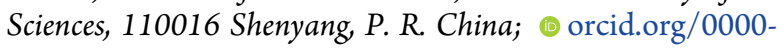
0003-4997-8870

Paul Hartmann - MATERIALS-Institute for Surface Technologies and Photonics, JOANNEUM RESEARCH, A8712 Niklasdorf, Austria; MATERIALS-Institute for Surface Technologies and Photonics, JOANNEUM RESEARCH, A-8160 Weiz, Austria

Wolfgang Waldhauser - MATERIALS-Institute for Surface Technologies and Photonics, JOANNEUM RESEARCH, A8712 Niklasdorf, Austria

Complete contact information is available at:

https://pubs.acs.org/10.1021/acsomega.1c03871

\section{Notes}

The authors declare no competing financial interest.

\section{ACKNOWLEDGMENTS}

We acknowledge funding by the Austrian Ministry of Transport, Innovation and Technology, the Austrian Research Promotion Agency (FFG) grant number 857181-GRATEC, and the Chinese Academy of Sciences (174321KYSB20160011). The authors acknowledge TU Wien Bibliothek for financial support through its Open Access Funding Program.

\section{REFERENCES}

(1) Fu, Y.; Hansson, J.; Liu, Y.; Chen, S.; Zehri, A.; Samani, M. K.; Wang, N.; Ni, Y.; Zhang, Y.; Zhang, Z.-B.; Wang, Q.; Li, M.; Lu, H.; Sledzinska, M.; Torres, C. M. S.; Volz, S.; Balandin, A. A.; Xu, X.; Liu, J. Graphene Related Materials for Thermal Management. 2D Mater. 2019, 7, 012001.

(2) Ma, T.; Liu, Z.; Wen, J.; Gao, Y.; Ren, X.; Chen, H.; Jin, C.; Ma, X.-L.; Xu, N.; Cheng, H.-M.; Ren, W. Tailoring the Thermal and Electrical Transport Properties of Graphene Films by Grain Size Engineering. Nat. Commun. 2017, 8, 14486.

(3) Gruber, E.; Wilhelm, R. A.; Pétuya, R.; Smejkal, V.; Kozubek, R.; Hierzenberger, A.; Bayer, B. C.; Aldazabal, I.; Kazansky, A. K.; Libisch, F.; Krasheninnikov, A. V.; Schleberger, M.; Facsko, S.; Borisov, A. G.; Arnau, A.; Aumayr, F. Ultrafast Electronic Response of Graphene to a Strong and Localized Electric Field. Nat. Commun. 2016, 7, 13948.

(4) Bayer, B. C.; Hofmann, S.; Castellarin-Cudia, C.; Blume, R.; Baehtz, C.; Esconjauregui, S.; Wirth, C. T.; Oliver, R. A.; Ducati, C.; Knop-Gericke, A.; Schlögl, R.; Goldoni, A.; Cepek, C.; Robertson, J. Support- Catalyst- Gas Interactions during Carbon Nanotube Growth on Metallic Ta Films. J. Phys. Chem. C 2011, 115, 43594369.

(5) Steiner, H.; Sauter, T.; Schlauf, M.; Schalkhammer, T.; Führinger, R.; Kieslinger, D. Challenges of In-Situ Thermal Characterization of Thin-Film Isolation Layers for Printed Electronics; IEEE, 2018; pp 803-808.

(6) Krzeminski, J.; Kanthamneni, A.; Wagner, D.; Detert, M.; Schmidt, B.; Jakubowska, M. Microscale Hybrid Flexible Circuit Printed With Aerosol Jet Technique. IEEE Trans. Nanotechnol. 2018, 17, 979-984.

(7) Jabari, E.; Ahmed, F.; Liravi, F.; Secor, E. B.; Lin, L.; Toyserkani, E. 2D Printing of Graphene: A Review. 2D Mater. 2019, 6, 042004.
(8) Ng, L.; Hu, G.; Howe, R.; Zhu, X.; Yang, Z.; Jones, C. G.; Hasan, T. Printing of Graphene and Related 2D Materials; Springer, 2018.

(9) Wilkinson, N. J.; Smith, M. A. A.; Kay, R. W.; Harris, R. A. A Review of Aerosol Jet Printing-a Non-Traditional Hybrid Process for Micro-Manufacturing. Int. J. Adv. Manuf. Technol. 2019, 105, $4599-4619$.

(10) Hoey, J. M.; Lutfurakhmanov, A.; Schulz, D. L.; Akhatov, I. S. A Review on Aerosol-Based Direct-Write and Its Applications for Microelectronics. J. Nanotechnol. 2012, 2012, 324380.

(11) Mahajan, A.; Frisbie, C. D.; Francis, L. F. Optimization of Aerosol Jet Printing for High-Resolution, High-Aspect Ratio Silver Lines. ACS Appl. Mater. Interfaces 2013, 5, 4856-4864.

(12) Rudorfer, A.; Pichler, H.; Palfinger, C.; Reil, F.; Wenzl, F.-P.; Hartmann, P. Additive Manufacturing Utilizing Aerosol Jet Printing Technology for LED Wire Bond Replacement; Society for Imaging Science and Technology, 2014; Vol. 2014, pp 451-454.

(13) Seifert, T.; Sowade, E.; Roscher, F.; Wiemer, M.; Gessner, T.; Baumann, R. R. Additive Manufacturing Technologies Compared: Morphology of Deposits of Silver Ink Using Inkjet and Aerosol Jet Printing. Ind. Eng. Chem. Res. 2015, 54, 769-779.

(14) Mashayekhi, M.; Winchester, L.; Evans, L.; Pease, T.; Laurila, M.-M.; Mantysalo, M.; Ogier, S.; Teres, L.; Carrabina, J. Evaluation of Aerosol, Superfine Inkjet, and Photolithography Printing Techniques for Metallization of Application Specific Printed Electronic Circuits. IEEE Trans. Electron Devices 2016, 63, 1246-1253.

(15) Rudorfer, A.; Tscherner, M.; Palfinger, C.; Reil, F.; Hartmann, P.; Seferis, I. E.; Zych, E.; Wenzl, F. P. A Study on Aerosol Jet Printing Technology in LED Module Manufacturing; International Society for Optics and Photonics, 2016; Vol. 9954, p 99540E.

(16) Jing, Q.; Choi, Y. S.; Smith, M.; Catić, N.; Ou, C.; Kar-Narayan, S. Aerosol-Jet Printed Fine-Featured Triboelectric Sensors for Motion Sensing. Adv. Mater. Technol. 2019, 4, 1800328.

(17) Alhendi, M.; Sivasubramony, R. S.; Weerawarne, D. L.; Iannotti, J.; Borgesen, P.; Poliks, M. D. Assessing Current-Carrying Capacity of Aerosol Jet Printed Conductors. Adv. Eng. Mater. 2020, 22,2000520

(18) Fujimoto, K. T.; Watkins, J. K.; Phero, T.; Litteken, D.; Tsai, K.; Bingham, T.; Ranganatha, K. L.; Johnson, B. C.; Deng, Z.; Jaques, B. Aerosol Jet Printed Capacitive Strain Gauge for Soft Structural Materials. npj Flexible Electron. 2020, 4, 32.

(19) Zhang, H.; Wang, B.; Brown, B. Aerosol-Jet-Printed CoFe2O4 Nanoparticle - Vertically Aligned Carbon Nanotube Composite for Microsupercapacitors. J. Phys. Chem. C 2021, 125, 7590-7597.

(20) Liu, R.; Shen, F.; Ding, H.; Lin, J.; Gu, W.; Cui, Z.; Zhang, T. All-Carbon-Based Field Effect Transistors Fabricated by Aerosol Jet Printing on Flexible Substrates. J. Micromech. Microeng. 2013, 23, 065027.

(21) Jabari, E.; Toyserkani, E. Micro-Scale Aerosol-Jet Printing of Graphene Interconnects. Carbon 2015, 91, 321-329.

(22) Jabari, E.; Toyserkani, E. Laser Heat Treatment of Aerosol-Jet Additive Manufactured Graphene Patterns. J. Phys. D: Appl. Phys. 2015, 48, 375503.

(23) Pandhi, T.; Kreit, E.; Aga, R.; Fujimoto, K.; Sharbati, M. T.; Khademi, S.; Chang, A. N.; Xiong, F.; Koehne, J.; Heckman, E. M.; Estrada, D. Electrical Transport and Power Dissipation in Aerosol-JetPrinted Graphene Interconnects. Sci. Rep. 2018, 8, 10842.

(24) Parate, K.; Rangnekar, S. V.; Jing, D.; Mendivelso-Perez, D. L.; Ding, S.; Secor, E. B.; Smith, E. A.; Hostetter, J. M.; Hersam, M. C.; Claussen, J. C. Aerosol-Jet-Printed Graphene Immunosensor for Label-Free Cytokine Monitoring in Serum. ACS Appl. Mater. Interfaces 2020, 12, 8592-8603.

(25) Parate, K.; Pola, C. C.; Rangnekar, S. V.; Mendivelso-Perez, D. L.; Smith, E. A.; Hersam, M. C.; Gomes, C. L.; Claussen, J. C. Aerosol-Jet-Printed Graphene Electrochemical Histamine Sensors for Food Safety Monitoring. 2D Mater. 2020, 7, 034002.

(26) Ha, M.; Seo, J.-W. T.; Prabhumirashi, P. L.; Zhang, W.; Geier, M. L.; Renn, M. J.; Kim, C. H.; Hersam, M. C.; Frisbie, C. D. Aerosol Jet Printed, Low Voltage, Electrolyte Gated Carbon Nanotube Ring 
Oscillators with Sub-5 $\mu$ s Stage Delays. Nano Lett. 2013, 13, 954960.

(27) Jones, C. S.; Lu, X.; Renn, M.; Stroder, M.; Shih, W.-S. AerosolJet-Printed, High-Speed, Flexible Thin-Film Transistor Made Using Single-Walled Carbon Nanotube Solution. Microelectron. Eng. 2010, 87, 434-437.

(28) Rother, M.; Brohmann, M.; Yang, S.; Grimm, S. B.; Schießl, S. P.; Graf, A.; Zaumseil, J. Aerosol-Jet Printing of Polymer-Sorted $(6,5)$ Carbon Nanotubes for Field-Effect Transistors with High Reproducibility. Adv. Electron. Mater. 2017, 3, 1700080.

(29) Cao, C.; Andrews, J. B.; Franklin, A. D. Completely Printed, Flexible, Stable, and Hysteresis-free Carbon Nanotube Thin-film Transistors via Aerosol Jet Printing. Adv. Electron. Mater. 2017, 3, 1700057.

(30) Cantù, E.; Tonello, S.; Abate, G.; Uberti, D.; Sardini, E.; Serpelloni, M. Aerosol Jet Printed 3D Electrochemical Sensors for Protein Detection. Sensors 2018, 18, 3719.

(31) Cardenas, J. A.; Catenacci, M. J.; Andrews, J. B.; Williams, N. X.; Wiley, B. J.; Franklin, A. D. In-Place Printing of Carbon Nanotube Transistors at Low Temperature. ACS Appl. Nano Mater. 2018, 1, $1863-1869$.

(32) Goh, G. L.; Agarwala, S.; Yeong, W. Y. Aerosol-Jet-Printed Preferentially Aligned Carbon Nanotube Twin-Lines for Printed Electronics. ACS Appl. Mater. Interfaces 2019, 11, 43719-43730.

(33) Lu, S.; Cardenas, J. A.; Worsley, R.; Williams, N. X.; Andrews, J. B.; Casiraghi, C.; Franklin, A. D. Flexible, Print-in-Place 1D-2D Thin-Film Transistors Using Aerosol Jet Printing. ACS Nano 2019, 13, 11263-11272.

(34) Lu, S.; Zheng, J.; Cardenas, J. A.; Williams, N. X.; Lin, Y.-C.; Franklin, A. D. Uniform and Stable Aerosol Jet Printing of Carbon Nanotube Thin-Film Transistors by Ink Temperature Control. ACS Appl. Mater. Interfaces 2020, 12, 43083-43089.

(35) Li, X.; Ren, Y.; Wang, X.; Shao, S.; Li, H.; Wu, L.; Liu, X.; Zhao, J. A Universal Method for High-Efficiency Immobilization of Semiconducting Carbon Nanotubes toward Fully Printed PaperBased Electronics. Adv. Electron. Mater. 2021, 7, 2001025.

(36) Cardenas, J. A.; Lu, S.; Williams, N. X.; Doherty, J. L.; Franklin, A. D. In-Place Printing of Flexible Electrolyte-Gated Carbon Nanotube Transistors with Enhanced Stability. IEEE Electron Device Lett. 2021, 42, 367-370.

(37) Nalawade, Y.; Pepper, J.; Harvey, A.; Griffin, A.; Caffrey, D.; Kelly, A. G.; Coleman, J. N. All-Printed Dielectric Capacitors from High-Permittivity, Liquid-Exfoliated BiOCl Nanosheets. ACS Appl. Electron. Mater. 2020, 2, 3233-3241.

(38) Yerokhin, A. L.; Nie, X.; Leyland, A.; Matthews, A.; Dowey, S. J. Plasma Electrolysis for Surface Engineering. Surf. Coat. Technol. 1999, 122, 73-93.

(39) Dehnavi, V.; Liu, X. Y.; Luan, B. L.; Shoesmith, D. W.; Rohani, S. Phase Transformation in Plasma Electrolytic Oxidation Coatings on 6061 Aluminum Alloy. Surf. Coat. Technol. 2014, 251, 106-114.

(40) Zhang, H.; Choi, J. P.; Moon, S. K.; Ngo, T. H. A Hybrid Multi-Objective Optimization of Aerosol Jet Printing Process via Response Surface Methodology. Addit. Manuf. 2020, 33, 101096.

(41) Ferrari, A. C. Raman Spectroscopy of Graphene and Graphite: Disorder, Electron-Phonon Coupling, Doping and Nonadiabatic Effects. Solid State Commun. 2007, 143, 47-57.

(42) Trusova, E. A.; Klimenko, I. V.; Afzal, A. M.; Shchegolikhin, A. N.; Jurina, L. V. Comparison of Oxygen-Free Graphene Sheets Obtained in DMF and DMF-Aqua Media. New J. Chem. 2021, 45, 10448-10458.

(43) Li, J.; Ye, F.; Vaziri, S.; Muhammed, M.; Lemme, M. C.; Östling, M. Efficient Inkjet Printing of Graphene. Adv. Mater. 2013, 25, 3985-3992.

(44) Fouquet, M.; Bayer, B. C.; Esconjauregui, S.; Blume, R.; Warner, J. H.; Hofmann, S.; Schlögl, R.; Thomsen, C.; Robertson, J. Highly Chiral-Selective Growth of Single-Walled Carbon Nanotubes with a Simple Monometallic Co Catalyst. Phys. Rev. B: Condens. Matter Mater. Phys. 2012, 85, 235411.
(45) Fouquet, M.; Bayer, B. C.; Esconjauregui, S.; Thomsen, C.; Hofmann, S.; Robertson, J. Effect of Catalyst Pretreatment on Chirality-Selective Growth of Single-Walled Carbon Nanotubes. J. Phys. Chem. C 2014, 118, 5773-5781.

(46) Panatarani, C.; Maulana, A. O.; Rianto, A.; Joni, I. M. Preparation of Graphite Oxide by Sodium Cholate Intercalation and Sonication from Indonesian Natural Graphite; AIP Publishing LLC, 2016; Vol. 1712, p 050025.

(47) Schroder, D. K. Semiconductor Material and Device Characterization; John Wiley \& Sons, 2015.

(48) Ren, W.; Cheng, H.-M. The Global Growth of Graphene. Nat. Nanotechnol. 2014, 9, 726-730.

(49) Wei, Q.; Pei, S.; Qian, X.; Liu, H.; Liu, Z.; Zhang, W.; Zhou, T.; Zhang, Z.; Zhang, X.; Cheng, H. M.; Ren, W. Superhigh Electromagnetic Interference Shielding of Ultrathin Aligned Pristine Graphene Nanosheets Film. Adv. Mater. 2020, 32, 1907411.

(50) Wu, Z.; Xu, C.; Ma, C.; Liu, Z.; Cheng, H. M.; Ren, W. Synergistic Effect of Aligned Graphene Nanosheets in Graphene Foam for High-performance Thermally Conductive Composites. Adv. Mater. 2019, 31, 1900199.

(51) Li, G.-X.; Hou, P.-X.; Luan, J.; Li, J.-C.; Li, X.; Wang, H.; Shi, C.; Liu, C.; Cheng, H.-M. A MnO2 Nanosheet/Single-Wall Carbon Nanotube Hybrid Fiber for Wearable Solid-State Supercapacitors. Carbon 2018, 140, 634-643.

(52) Elibol, K.; Bayer, B. C.; Hummel, S.; Kotakoski, J.; Argentero, G.; Meyer, J. C. Visualising the Strain Distribution in Suspended Two-Dimensional Materials under Local Deformation. Sci. Rep. 2016, 6, 28485 . 